\title{
Consistent condom use among sexually active HIV-positive women in Amhara region, Ethiopia
}

This article was published in the following Dove Press journal:

Open Access Journal of Contraception

3 November 2014

Number of times this article has been viewed

\section{Kefyalew Addis Alene \\ Institute of Public Health, College of Medicine and Health Sciences, University of Gondar, Gondar, Ethiopia}

Correspondence: Kefyalew Addis Alene 196 University of Gondar,

Gondar, Ethiopia

Email kefadis@gmail.com
Background: Consistent condom use has been described as the most effective way to prevent both sexually transmitted infections and HIV transmission among people living with HIV. Therefore, this study assessed the prevalence and factors associated with condom use among sexually active HIV-positive women in Amhara region referral hospitals, Ethiopia.

Methods: An institution-based cross-sectional study design was conducted from April to June, 2013 in Amhara region referral hospitals. A standardized questionnaire was used to collect the data. The data were entered into EPI INFO version 3.5.1 statistical software and analyzed by SPSS version 20.0. Binary logistic regression model was used to identify the associated factors. Odds ratios with 95\% confidence intervals (CIs) were calculated to assess the strength of association. Results: A total of 351 sexually active HIV-positive women were interviewed. Consistent condom use among sexually active HIV-positive women was found to be $56.7 \%(51.7 \%-61.9 \%)$. Being in the age groups 30-34 years (adjusted odds ratio [AOR]: 2.82, 95\% CI 1.31, 6.08) and 35-39 years (AOR: 2.64, 95\% CI 1.15, 6.08), having a relatively large family (three to five family members) (AOR: $2.5495 \%$ CI 1.57, 4.12) and more than five family members (AOR: 1.69 95\% CI 0.79, 3.63), and being Muslim or Protestant (AOR: 0.52 95\% CI 0.33, 0.84) were variables associated with consistent condom use.

Conclusion: Consistent condom use among sexually active HIV-positive women in Amhara region referral hospital was low, suggesting an urgent need for intervention through the involvement of a religious leader.

Keywords: condom use, HIV-positive women, Amhara region, Ethiopia

\section{Background}

Nearly $68 \%$ of all people living with HIV worldwide live in sub-Saharan Africa among which 59\% are women. About 1.9 million new infections were reported in sub-Saharan Africa in 2010, representing more than two-thirds (70\%) of all new infections globally. ${ }^{1}$

Overall, HIV prevalence in Ethiopia is higher for women than men in reproductive age groups. In the year 2005, the HIV/AIDS prevalence rate in Ethiopia was $0.9 \%$ among men and 1.9\% among women. Similarly, in the year 2011 the HIV prevalence rate among women aged $15-49$ was $1.9 \%$, and $1.0 \%$ among men. ${ }^{2,3}$

The large number of HIV infections among women in the reproductive age group has consequences for both their own health and public health. HIV-positive women are at increased risk for sexually transmitted infections (STIs). ${ }^{4-6}$ The presence of STIs can also increase the risk of mother-to-child HIV transmission and leads to adverse birth outcomes. ${ }^{4,5}$ 
Dual protection is the prevention of two unplanned and undesirable outcomes - unintended pregnancy and HIV infection, and can be achieved through the use of condoms. In Ethiopia, where the most important route of HIV transmission is unprotected heterosexual intercourse, practice of dual protection is low. ${ }^{2,7}$ However, like in many countries in sub-Saharan Africa, women in Ethiopia are more vulnerable for HIV infection than males. ${ }^{3,8}$ Studies found that only $1 \%$ of rural females and $50 \%$ of urban females used a condom when they had sexual intercourse for the first time, but detailed knowledge about levels of condom use among HIV women in Ethiopia is currently lacking. ${ }^{9-11}$

Protected sexual intercourse through consistent condom use has been described as the most effective way to prevent both STI and HIV transmission among people living with HIV. Studies showed that condom use at last sexual intercourse is associated with HIV prevalence. ${ }^{12,13}$

Several studies have assessed that behavioral, personal, and cultural obstacles prohibit enacting and maintaining consistent condom use, ${ }^{14-16}$ however many of these studies have focused on males. Considering the high rate of HIV infections among Ethiopian women and the prolonged life span of those living with HIV due to advances in antiretroviral therapies, detecting the factors of consistent condom use among women living with HIV will have a public health importance in the prevention of HIV. ${ }^{17}$

Although there is considerable research in the study area on condom use in women at risk for HIV/AIDS, I am not aware of research investigating factors related to condom use among sexually active women who are known to be HIV-positive. Therefore, this study assessed the prevalence and associated factors of condom use among sexually active HIV-positive women in Amhara region referral hospitals, Ethiopia.

\section{Methods}

\section{Study setting and design}

An institution-based cross-sectional study design was conducted from April to June 2013 in Amhara region referral hospitals. Amhara region is one of the nine regional states located in the northwestern part of Ethiopia. Based on the 2007 Census, the region has a total of $17,221,976$ populations of which $8,580,396$ were women. ${ }^{18}$ Currently, the region has five referral hospitals, from these the study was conducted among three hospitals (Gondar University Referral Hospital, Dessie Referral Hospital, and Debremarkos Referral Hospital). These three hospitals are serving as a referral center for general hospitals in the area. They had a total of 35,063 people living with HIV ever enrolled in the antiretroviral therapy (ART) clinic and 6,998 women were on ART.

\section{Study population}

The participants of this study were sexually active HIVpositive women aged 15-49 years who were on ART and had at least one visit to the ART clinic.

\section{Sampling procedures}

The sample size was determined by using single population proportion formula by considering the following assumptions: $95 \%$ confidence interval (CI), 17.2\% proportion of condom use according to the Ethiopian Demography and Health Survey 2011 report $^{2}$ and $4 \%$ margin of error. By adding 5\% non-response rate, the final sample size was 358 . Stratified sampling technique was employed in order to select a representative sample of HIV-positive women from each hospital. The samples were proportionally allocated to each hospital and respondents were selected using systematic sampling technique.

\section{Data collection}

Data were collected by an interview technique using a structured questionnaire which was first prepared in English and then translated to the local language (Amharic). The prepared questionnaire was pre-tested and structured. The returned questionnaires were checked for completeness on site by the supervisor. One supervisor and two female data collectors at each hospital, with a total of nine personnel members participated in the data collection process. Intensive training was given to data collectors and supervisor for 1 day on how to approach study subjects, how to use the questionnaire, how to conduct the data, and on the objective of the study.

The dependent variable, consistent condom use, was defined as reported use of condoms during every vaginal sex episode with a male partner in the last 30 days. ${ }^{19}$ The independent variables included sociodemographic characteristics like age, sex, marital status, residence, family size, occupation, disclosure of HIV status to partner, knowledge of sexual partner's HIV status (positive, negative, unknown), family planning and desire of future pregnancy. Clinical data like cluster of differentiation (CD) 4 count were collected from the patient's chart.

\section{Data processing and analysis}

The data were entered into EPI INFO version 3.5.1 statistical software and analyzed by SPSS version 20.0 (IBM Corporation, Armonk, NY, USA). Frequencies and cross 
tabulations were used to summarize descriptive statistics. Binary logistic regression model was used to identify variables associated with consistent condom use. Variables having a $P$-value $\leq 0.2$ in the bivariate analysis were entered into a multivariate analysis for controlling the possible effect of confounders. Odds ratios with $95 \%$ CIs were calculated.

\section{Ethical consideration}

Ethical clearance was obtained from the Ethical Review Board of the University of Gondar. Permission was obtained from the hospitals' administration and the ART focal persons at each hospital. After the purpose of the study was explained, verbal consent was obtained from each of the study participants. Interviews were carried out privately in a separate room in the hospitals. Participants were informed that participation was on a voluntary basis and that they can withdraw at any time if they are not comfortable about the questionnaire. Names or personal identifiers were not included in the written questionnaires to ensure participants' confidentiality.

\section{Results}

\section{Sociodemographic and clinical characteristics of the study participants}

A total of 351 (with $98.0 \%$ response rate) sexually active HIV-positive women were interviewed. Half (50.4\%) of the study participants were from Dessie Referral Hospital and in the age group of 30-39 years.

The majority of the study participants were urban dwellers (90\%), married (86.6\%), and Amhara ethnic group (96\%). About two-thirds (66.7\%) and one-third (31.6\%) were orthodox Christians and attained secondary education, respectively. One hundred and fifty-nine (45.3\%) of the study participants were housewives and one-third (33.3\%) of them had a monthly income of $>1,000.00$ Ethiopian Birr per month.

Almost half (49.2\%) of the study participants had a family of 3-5 and desired future pregnancy (55.8\%). About half (53.6\%) of the study participants were diagnosed HIV-positive 4 years ago and did not give birth since HIV diagnosis (56.6\%) while $34(9.7 \%)$ of them had an HIV-positive child. The median CD4 count of the study participants was $450 \mathrm{cell} / \mathrm{uL}$ (interquartile range $=316-600)$. Almost all of the married women (98.0\%) disclosed their HIV status to their husbands, and most of their husbands were HIV-positive (73.7\%) (Table 1).

\section{Consistent condom use and associated factors}

Of the 351 sexually active HIV-positive women, 199 (56.7\%, 95\% CI: $51.7 \%-61.9 \%$ ) were using condoms consistently.
Table I Characteristics of study participants in Amhara region referral hospital, Ethiopia, 2013 ( $n=35 \mathrm{I})$

\begin{tabular}{|c|c|c|}
\hline Variables & Frequency & Percent \\
\hline \multicolumn{3}{|l|}{ Hospital } \\
\hline Gondar & 101 & 28.8 \\
\hline Dessie & 177 & 50.4 \\
\hline Debremarkos & 73 & 20.8 \\
\hline \multicolumn{3}{|l|}{ Age group (years) } \\
\hline $15-24$ & 29 & 8.3 \\
\hline $25-29$ & 102 & 29.1 \\
\hline $30-34$ & 110 & 31.3 \\
\hline $35-39$ & 68 & 19.4 \\
\hline $40-49$ & 42 & 12.0 \\
\hline \multicolumn{3}{|l|}{ Residence } \\
\hline Urban & 316 & 90.0 \\
\hline Rural & 35 & 10.0 \\
\hline \multicolumn{3}{|l|}{ Marital status } \\
\hline Married & 304 & 86.6 \\
\hline Single & 11 & 3.1 \\
\hline Divorced & 18 & 5.1 \\
\hline Widowed & 13 & 3.7 \\
\hline Separated & 5 & 1.4 \\
\hline \multicolumn{3}{|l|}{ Religion } \\
\hline Orthodox Christian & 234 & 66.7 \\
\hline Muslim & III & 31.6 \\
\hline Protestant & 6 & 1.7 \\
\hline \multicolumn{3}{|l|}{ Ethnicity } \\
\hline Amhara & 339 & 96.6 \\
\hline Tigray & 9 & 2.6 \\
\hline Others & 3 & 0.9 \\
\hline \multicolumn{3}{|l|}{ Educational level } \\
\hline Not able to read and write & 88 & 25.1 \\
\hline Able to read and write & 54 & 15.4 \\
\hline Primary school (Grades I-8) & 72 & 20.5 \\
\hline Secondary school (Grades 9-12) & III & 31.6 \\
\hline College or university level & 26 & 7.4 \\
\hline \multicolumn{3}{|l|}{ Occupation } \\
\hline Daily laborer & 64 & 18.2 \\
\hline Farmer & 27 & 7.7 \\
\hline Government employee & 34 & 9.7 \\
\hline Housewife & 159 & 45.3 \\
\hline Merchant & 44 & 12.5 \\
\hline Others & 23 & 6.6 \\
\hline \multicolumn{3}{|c|}{ Monthly household income (Birr) } \\
\hline$<300.00$ & 65 & 18.5 \\
\hline $300.00-600.00$ & 69 & 19.7 \\
\hline $601.00-1,000.00$ & 100 & 28.5 \\
\hline$>1,000.00$ & 117 & 33.3 \\
\hline \multicolumn{3}{|l|}{ Family size } \\
\hline$<3$ & 142 & 40.5 \\
\hline $3-5$ & $17 \mid$ & 48.7 \\
\hline$>5$ & 38 & 10.8 \\
\hline \multicolumn{3}{|l|}{ Desires future pregnancy } \\
\hline Yes & 148 & 42.2 \\
\hline No & 203 & 56.6 \\
\hline \multicolumn{3}{|l|}{ Gave birth after HIV diagnosis } \\
\hline Yes & 155 & 44.2 \\
\hline No & 196 & 55.8 \\
\hline
\end{tabular}


Table I (Continued)

\begin{tabular}{lll}
\hline Variables & Frequency & Percent \\
\hline Has or had an HIV-positive child & & \\
Yes & 34 & 9.7 \\
No & 299 & 85.2 \\
I do not know & 18 & 5.1 \\
Time since HIV diagnosis (years) & & \\
$\leq$ I year & 33 & 9.4 \\
2-3 years & 130 & 37.0 \\
$\geq 4$ years & 188 & 53.6 \\
Current CD4 count & & \\
$<200$ & 25 & 7.1 \\
200-350 & 92 & 26.2 \\
$35 I-500$ & 103 & 29.6 \\
$>500$ & 130 & 37.0 \\
HIV status of husband (n=304) & & \\
Positive & 224 & 73.7 \\
Negative & 67 & 23.0 \\
I do not know & 10 & 3.3 \\
Disclosed HIV status to partner $(\mathbf{n}=304)$ & 98.0 \\
Yes & 298 & 2.0 \\
No & 3 & \\
\hline Abbreviation: CD4, clustr of &
\end{tabular}

Abbreviation: CD4, cluster of differentiation 4 .

In the bivariate analysis, age, religion, family size, desired future pregnancy, and having an HIV-positive child were factors associated with consistent condom use. However, in the multivariate analysis age, religion, and family size remained significantly and independently associated with consistent condom use.

HIV-positive women aged between 30-34 years (adjusted odds ratio [AOR]: 2.82, 95\% CI 1.31, 6.08) and 35-39 years (AOR: 2.64, 95\% CI 1.15, 6.08) were more likely to use condoms consistently than women aged between 40-49 years. HIV-positive women with a relatively large family of 3-5 (AOR: $2.5495 \%$ CI 1.57, 4.12) and more than five (AOR: $1.6995 \%$ CI $0.79,3.63$ ) were more likely to use condoms consistently than HIV-positive women with small families $(<3)$. In addition to this, HIVpositive women who are Muslim or Protestant were 48\% less likely to use condoms consistently than HIV-positive women who are Orthodox Christians (AOR: 0.52 95\% CI $0.33,0.84$ ) (Table 2).

\section{Discussion}

This study provides information on condom use by sexually active HIV-positive women in Amhara region, Ethiopia. It was found that among sexually active HIV-positive women, $56.7 \%(51.7 \%-61.9 \%)$ used condoms consistently in the last month. This is similar to studies from HIV-positive women in Italy (60\%), ${ }^{20}$ and African countries like rural Uganda $(53 \%)^{16,21}$ and Kampala $(55 \%) .{ }^{22}$
Table 2 Factors associated with consistent condom use among HIV-positive women in Amhara region referral hospital, 2013

\begin{tabular}{|c|c|c|c|c|}
\hline \multirow[t]{2}{*}{ Variables } & \multicolumn{2}{|c|}{$\begin{array}{l}\text { Consistent } \\
\text { condom } \\
\text { use }\end{array}$} & \multirow[t]{2}{*}{ COR $(95 \% \mathrm{Cl})$} & \multirow[t]{2}{*}{ AOR $(95 \% \mathrm{Cl})$} \\
\hline & Yes & No & & \\
\hline \multicolumn{5}{|l|}{ Age group (years) } \\
\hline $15-24$ & 15 & 14 & $1.57(0.60,4.09)$ & $2.29(0.81,6.45)$ \\
\hline $25-29$ & 55 & 47 & I.72 $(0.83,3.56)$ & I.83 $(0.85,3.97)$ \\
\hline $30-34$ & 70 & 40 & $2.57(1.24,5.33)$ & $2.82(1.31,6.08)$ \\
\hline $35-39$ & 42 & 26 & $2.37(\mathrm{I} .08,5.2 \mathrm{I})$ & $2.64(1.15,6.08)$ \\
\hline $40-49$ & 17 & 25 & 1.00 & 1.00 \\
\hline \multicolumn{5}{|l|}{ Marital status } \\
\hline Has partner & 177 & 127 & 1.00 & \\
\hline Has no partner & 22 & 25 & $0.63(0.34,1.17)$ & \\
\hline \multicolumn{5}{|l|}{ Religion } \\
\hline Orthodox & 143 & 91 & 1.00 & 1.00 \\
\hline \multicolumn{5}{|l|}{ Christian } \\
\hline Muslim/Protestant & 56 & 61 & $0.58(0.37,0.91)$ & $0.52(0.33,0.84)$ \\
\hline \multicolumn{5}{|c|}{ Monthly household income (Birr) } \\
\hline$<300.00$ & 37 & 28 & $1.17(0.63,2.15)$ & \\
\hline $300.00-600.00$ & 35 & 34 & $0.91(0.50,1.65)$ & \\
\hline $601.00-1,000.00$ & 65 & 35 & I.64 $(0.95,2.85)$ & \\
\hline$>1,000.00$ & 62 & 55 & 1.00 & \\
\hline \multicolumn{5}{|l|}{ Family size } \\
\hline$<3$ & 64 & 78 & 1.00 & 1.00 \\
\hline $3-5$ & 115 & 56 & $2.50(1.58,3.96)$ & $2.54(1.57,4.12)$ \\
\hline$>5$ & 20 & 18 & $1.35(0.66,2.77)$ & $1.69(0.79,3.63)$ \\
\hline \multicolumn{5}{|c|}{ Desires future pregnancy } \\
\hline Yes & 72 & 76 & 1.00 & \\
\hline No & 127 & 76 & $1.76(I .14,2.7 I)$ & \\
\hline \multicolumn{5}{|c|}{ Has or had an HIV-positive child } \\
\hline Yes & 6 & 12 & 1.00 & \\
\hline No & 22 & 12 & $3.66(1.09,12.25)$ & \\
\hline I do not know & $|7|$ & 128 & $2.67(0.9,7.31)$ & \\
\hline \multicolumn{5}{|c|}{ Time since HIV diagnosis (years) } \\
\hline$\leq \mathrm{I}$ year & 16 & 17 & 1.00 & \\
\hline $2-3$ years & 62 & 48 & $\mathrm{I} .8 \mathrm{I}(0.84,3.92)$ & \\
\hline$\geq 4$ years & 101 & 87 & $1.23(0.58,2.58)$ & \\
\hline
\end{tabular}

Abbreviations: $\mathrm{AOR}$, adjusted odds ratio; $\mathrm{Cl}$, confidence interval; $\mathrm{COR}$, crude odds ratio.

However, it is quite low compared to findings from studies conducted among ART patients in India (87\%) and other settings, ${ }^{23-25}$ although the participants in India were financing treatment themselves, so they might have been economically stable. Socioeconomic status has been found to influence consistent condom use. The low level of consistent condom use found in this study has to be a concern because the study participants were sexually active HIV-positive women. In the current study, approximately half of women living with HIV reported inconsistent condom use with their regular partners, thus posing health risks to themselves and their partners.

The results of this study and an other study conducted in Nigeri ${ }^{26}$ showed that a relatively younger age in women was a determinant factor for consistent condom use. 
Women in the age group of 30-39 years were more likely to use condoms consistently than women in the age group of 40-49 years. This could be due to the fact that HIV-positive women are using condoms to prevent unwanted pregnancy. Due to the biological fact that older women will become menopausal, they are less likely to use condoms. It is also supported by this study that women who have large families are more likely to use condoms than their counterparts. This implied that sexually active older women were at higher risk of STI and focal for HIV transmission to their husbands as a significant number $(25.5 \%)$ of their partners' HIV status were not known. Therefore, there is a need to improve women's understanding of the importance of simultaneous pregnancy and STD prevention, particularly in high-risk situations such as concurrent partnerships, through consistent condom use.

The other possible explanation for this finding is that the younger HIV-positive individuals may have greater information on HIV/AIDS and a sense of personal responsibility to not infect their partners in contrast to older HIV-positive individuals. This greater sense of personal responsibility can also serve as motivation to increase their enquiries for HIV information to practice safer sex with their partners.

In this study, Muslim/Protestant women were less likely to use condoms consistently than orthodox Christian women. This result suggested that religious leaders should be actively involved in the fight against HIV/AIDS by educating the community on HIV/AIDS prevention mechanisms.

This study was conducted with a certain limitation. Consistent condom use was assessed based on self-reported information which is subject to socially desirable bias, maybe over reported. In addition, the generalizability of this study may be limited because HIV-positive individuals who visited the HIV-clinic might be different from those who did not.

\section{Conclusion}

Consistent condom use among sexually active HIV-positive women in Amhara region referral hospitals was low, suggesting an urgent need for intervention through the involvement of religious leaders. This low condom use also highlights the need for the regional HIV/AIDS prevention and control office to expand their efforts in promoting condom use for this group especially for Muslim/Protestant and young HIVpositive women. Age, family size, and religion were found to be factors associated with consistent condom use of sexually active HIV-positive women. These factors can be used to design interventions for those who know they are infected at the regional level.

\section{Acknowledgment}

The author would like to thank the data collectors and supervisors for their effort during data collection.

\section{Disclosure}

The author reports no conflicts of interest in this work.

\section{References}

1. World Health Organization. Key Facts on HIV Epidemic and Progress in Regions and Countries in 2010, Based on Progress Report 2011: Global HIV/AIDS Response. Geneva: World Health Organization; 2012. Available from: http://www.who.int/hiv/pub/progress_report2011/ regional_facts/en/. Accessed September 20, 2014.

2. Central Statistical Agency Ethiopia. Ethiopia Demographic and Health Survey 2011. Addis Ababa: Ethiopia Central Statistical Agency; 2012. Available from: http://www.usaid.gov/sites/default/ files/documents/1860/Demographic\%20Health\%20Survey $\% 20$ 2011\%20Ethiopia\%20Final\%20Report.pdf. Accessed September 20, 2014.

3. Central Statistical Agency Ethiopia. Ethiopia Demographic and Health Survey 2005. Addis Ababa: Ethiopia Central Statistical Agency; 2006. Available from: http://www.dhsprogram.com/pubs/pdf/FR179/ FR179\%5B23June2011\%5D.pdf. Accessed September 20, 2014.

4. John GC, Nduati RW, Mbori-Ngacha DA, et al. Correlates of motherto-child human immunodeficiency virus type 1 (HIV- 1) transmission: Association with maternal plasma HIV- 1 RNA load, genital HIV-1 DNA shedding, and breast infections. J Infect Dis. 2001;183(2): 206-212.

5. Landes M, Thorne C, Barlow P, et al. Prevalence of sexually transmitted infections in HIV-1 infected pregnant women in Europe. Eur $J$ Epidemiol. 2007;22(12):925-936.

6. McClelland RS, Lavreys L, Katingima C, et al. Contribution of HIV-1 infection to acquisition of sexually transmitted disease: a 10-year prospective study. J Infect Dis. 2005;191(3):333-338.

7. Teklu T, Davey G. Which factors influence North Ethiopian adults' use of dual protection from unintended pregnancy and HIV/AIDS? Ethiopian Journal of Health Development. 2008;22(3):226-223.

8. Gregson S, Nyamukapa CA, Garnett GP, et al. Sexual mixing patterns and sex-differentials in teenage exposure to HIV infection in rural Zimbabwe. Lancet. 2002;359(9321):1896-1903.

9. Wouhabe M. Sexual behaviour, knowledge and awareness of related reproductive health issues among single youth in Ethiopia. Afr J Reprod Health. 2007;11(1):14-21.

10. Adamu R, Mulatu MS, Haile SI. Patterns and correlates of sexual initiation, sexual risk behaviors and condom use among secondary school students in Ethiopia. Ethiop Med J. 2003;41(2):163-177.

11. Taffa N, Sundby J, Bjune G. Reproductive health perceptions, beliefs and sexual risk- taking among youth in Addis Ababa, Ethiopia. Patient Educ Couns. 2003;49(2):165-169.

12. Mansergh G, Naorat S, Jommaroeng R, et al. Inconsistent condom use with steady and casual partners and associated factors among sexuallyactive men who have sex with men in Bangkok, Thailand. AIDS Behav. 2006;10(6):743-751.

13. Dintwa KF. Factors associated with nonuse of condom for sexually active Botswana women. Health Care Women Int. 2010;31(1): 37-52.

14. Yalew E, Zegeye DT, Meseret S. Patterns of condom use and associated factors among adult HIV positive clients in North Western Ethiopia: a comparative cross sectional study. BMC Public Health. 2012;12:308.

15. Conserv D, Sevilla L, Younge S, Mbwambo J, King G. Condom Use among HIV-Positive Sexually Active Adults and Partner's HIV Status in Dares Salaam, Tanzania. J Health Care Poor Underserved. 2012;23(1): 191-203. 
16. Miner MH, Robinson BE, Hoffman L, Albright CL, Bockting WO. Improving safer sex measures through the inclusion of relationship and partner characteristics. AIDS Care. 2002;14(6):827-837.

17. Kloos H, Hialemariam D, Lindtjørn B. The AIDS Epidemic in a LowIncome Country: Ethiopia. Research in Human Ecology. 2007;14(1): 39-55.

18. Central Statistical Agency Ethiopia. Summary and Statistical Report of the 2007 Population and Housing Census of Ethiopia. Addis Ababa: Central Statistical Agency; 2008. Available from: https://www.scribd. com/doc/28289334/Summary-and-Statistical-Report-of-the-2007. Accessed September 20,2014.

19. Wingood GM, DiClemente RJ, Mikhail I, et al. A randomized controlled trial to reduce HIV transmission risk behaviors and STDs among women living with HIV: The WiLLOW Program. J Acquir Immune Defic Syndr. 2004;37 Suppl 2:S58-S67.

20. Cicconi P, Monforte Ad, Castagna A, et al. Inconsistent condom use among HIV-positive women in the "Treatment as Prevention Era": data from the Italian DIDI study. J Int AIDS Soc. 2013;16:18591.

21. Bunnell R, Ekwaru JP, Solberg P, et al. Changes in sexual behavior and risk of HIV transmission after antiretroviral therapy and prevention interventions in rural Uganda. AIDS. 2006;20(1):85-92.
22. Bateganya M, Colfax G, Shafer LA, et al. Antiretroviral therapy and sexual behavior: a comparative study between antiretroviral- naive and -experienced patients at an urban HIV/AIDS care and research center in Kampala, Uganda. AIDS Patient Care STDS. 2005;19(11):760-768.

23. Avina S, Gupta I, Pujari S, Sengar AK, Garg R, Weiss E. Examining Adherence and Sexual Behaviour among Patients on Antiretroviral Therapy in India. Horizons Final Report Washington DC: Population Council; 2006. Available from: http://pdf.usaid.gov/pdf_docs/ PNADG546.pdf. Accessed September 20, 2014.

24. Wilson TE, Gore ME, Greenblatt R, et al. Changes in sexual behaviour among HIV-infected women after initiation of HAART. Am J Public Health. 2004;94(7):1141-1146.

25. Quinn TC, Wawer MJ, Sewankambo N, et al. Viral load and heterosexual transmission of human immunodeficiency virus type $1 . \mathrm{N} \mathrm{Engl}$ J Med. 2000;342(13):921-929.

26. Akinyemi JO, Awolude OA, Adewole IF, Kanki PJ. Condom use among antiretroviral therapy patients in Ibadan, Nigeria. $J$ Infect Dev Ctries. 2010;4(8):495-502.
Open Access Journal of Contraception

\section{Publish your work in this journal}

Open Access Journal of Contraception is an international, peerreviewed, open access, online journal, publishing original research, reports, reviews and commentaries on all areas of contraception. In addition to clinical research, demographics and health-related aspects, the journal welcomes new findings in animal and preclinical

\section{Dovepress}

studies relating to understanding the biological mechanisms and practical development of new contraceptive agents. The manuscript management system is completely online and includes a very quick and fair peer-review system. Visit http://www.dovepress.com/testimonials.php to read real quotes from published authors. 